OPEN ACCESS

Edited by:

Sara Pilotto,

University of Verona, Italy

Reviewed by:

Alexandre Reuben,

University of Texas MD Anderson Cancer Center, United States

Francesco Passiglia,

University of Turin, Italy

*Correspondence:

Marcin Nicos

marcin.nicos@um/ub.pl

Specialty section:

This article was submitted to

Thoracic Oncology,

a section of the journal

Frontiers in Oncology

Received: 03 June 2020 Accepted: 09 November 2020 Published: 04 December 2020

Citation:

Nicoś $M$, Krawczyk P, Crosetto $N$ and Milanowski J (2020) The Role of Intratumor Heterogeneity in the

Response of Metastatic Non-Small

Cell Lung Cancer to Immune

Checkpoint Inhibitors.

Front. Oncol. 10:569202.

doi: 10.3389/fonc.2020.569202

\section{The Role of Intratumor Heterogeneity in the Response of Metastatic Non- Small Cell Lung Cancer to Immune Checkpoint Inhibitors}

\author{
Marcin Nicos ${ }^{1,2^{*}}$, Paweł Krawczyk ${ }^{1}$, Nicola Crosetto ${ }^{2}$ and Janusz Milanowski ${ }^{1}$ \\ ${ }^{1}$ Department of Pneumonology, Oncology and Allergology, Medical University of Lublin, Lublin, Poland, 2 Science for Life \\ Laboratory, Department of Medical Biochemistry and Biophysics, Karolinska Institutet, Stockholm, Sweden
}

Immune checkpoint inhibitors $(\mathrm{ICls})$ represent one of the most promising therapeutic approaches in metastatic non-small cell lung cancer (M-NSCLC). Unfortunately, approximately $50-75 \%$ of patients do not respond to this treatment modality. Intratumor heterogeneity (ITH) at the genetic and phenotypic level is considered as a major cause of anticancer therapy failure, including resistance to $\mathrm{ICls}$. Recent observations suggest that spatial heterogeneity in the composition and spatial organization of the tumor microenvironment plays a major role in the response of $\mathrm{M}$ NSCLC patients to ICls. In this mini review, we first present a brief overview of the use of ICls in M-NSCLC. We then discuss the role of genetic and non-genetic ITH on the efficacy of ICls in patients with M-NSCLC.

Keywords: metastatic non-small cell lung cancer (NSCLC), tumor heterogeneity, immunotherapy, tumor mutation burden, tumor microenvironment, neoantigens, programmed-death 1 (PD-1), programmed-death ligand 1 (PD-L1)

\section{IMMUNE CHECKPOINT INHIBITORS IN METASTATIC NON-SMALL CELL LUNG CANCER: AN OVERVIEW}

Understanding the interactions between the immune system and cancer cells has greatly advanced our knowledge of the mechanisms of tumor growth and progression (1). By now, it is clear that the immune system plays a pivotal role not only in eradicating the disease in cancer patients, but also in promoting a long-lasting immunity (2). This key observation has paved the way to the development of immunomodulating agents and opened the era of cancer immunotherapy (3), which culminated with the assignment of the Nobel Price to James P. Allison and Tasuku Honjo in 2018 (4). Modulation of interactions between T-cells, antigen-presenting cells, and tumor cells has helped unleash suppressed immune responses and increase the effective elimination of cancer cells $(1,2)$.

The availability of immune checkpoint inhibitors (ICIs) has radically changed the management of patients affected by M-NSCLC (3). Commonly used ICIs in these patients include the monoclonal antibodies: nivolumab (5-8), pembrolizumab (9-12), durvalumab (13), atezolizumab (14-16), and avelumab (17), which act by targeting immune checkpoints expressed by tumor infiltrating lymphocytes (TILs) - programmed-death 1 (PD-1)-or expressed by cancer and tumor infiltrating immune cells- programmed-death ligand 1 (PD-L1) $(18,19)$. The selection of which ICI to use depends on the expression of PD-L1, which can be evaluated using various assays, whose 
clinical validity has been assessed in numerous clinical trials $(5,6$, $8-10,12-16)$. ICIs have proven to be better tolerated than standard chemotherapy $(2,6,10)$. However, the response to single-agent ICI therapy is not durable, and only a minority of patients have a prolonged benefit $(2,9,14)$. Moreover, there is now evidence that dual blockade of CTLA- 4 and PD-1 receptors is sufficient to induce unique cellular responses compared with agents blocking these receptors given alone to M-NSCLC patients (20).

Most studies conducted so far have shown that the response to ICIs in M-NSCLC patients is independent of the histological subtype (squamous or non-squamous histology) $(1,3)$. However, many factors contribute to the extent of the response as well as the risk of developing resistance to ICIs in these patients $(1,3)$. In this review, we discuss how both genetic and non-genetic intratumor heterogeneity (ITH) influences the immunogenicity of M-NSCLC, and highlight the importance of integrated genomic, pathologic and immunologic analyses to refine the selection of M-NSCLC patients who may be candidates to treatment with ICIs.

\section{DETERMINANTS OF RESPONSE TO IMMUNE CHECKPOINT INHIBITORS}

\section{The Tumor Microenvironment}

A key determinant of the response of M-NSCLC patients to ICI therapy is the tumor microenvironment (TME) (21-23). The TME is the ensemble of tumor cells, non-tumor cells including carcinoma-associated fibroblasts and immune cells, extracellular matrix as well as blood and lymphatic vessels composing a neoplastic lesion (24-27). Among malignant cells, the TME contains tumor cell subclones expressing phenotypic traits that protect them from the hosts immune system and support their ability to invade the extracellular matrix and extravasate $(22,28)$. On the other hand, the TME also contains a rich repertoire of tumor-infiltrating immune cells including $\mathrm{T}$ and B-cells, neutrophils, dendritic cells, myeloid-derived suppressor cells, or tumor-associated macrophages, that normally constitute a natural barrier to carcinogenesis $(22,24)$. Inside the TME, the activity of these immune cells is strongly suppressed by cytokines, growth factors and matrix re-modelling enzymes secreted from cancer cells $(22,24,29)$. These immunosuppressive effects are further intensified by the intensive aerobic glycolysis metabolism, which is observed in many tumors $(22,24-26)$. The TME is able to control the accumulation of $\mathrm{T}$-cells inside the tumor by multiple regulatory mechanisms $(30,31)$. Notably, the type, density and location of immune cells within the TME play an important role in the progression of the disease and have both predictive and prognostic values in patients with M-NSCLC $(31,32)$. Based on the density and location of CD4 and CD8-positive TILs in the tumor center and infiltration margins of TME, tumors have been classified as "hot" when they have a high number/density of TILs or as "cold" when they contain a low number of TILs $(30,33,34)$. M-NSCLCs generally fall into the "hot" category and, accordingly, patients with M-NSCLC respond relatively well to ICIs (21). However, the response is generally limited to a small subset of patients $(21,35)$, which is likely due to differences in the cellular composition and spatial organization of the TME, as we discuss further.

\section{Programmed-Death 1 and Programmed- Death Ligand 1}

A key feature of M-NSCLCs that respond to ICIs is the expression of PD-1 and its ligand PD-L1 in the TILs and tumor cells of the TME $(22,29,33)$. PD-L1 is expressed on the surface of tumor cells and binds to its cognate $\mathrm{PD}-1$ receptor on the surface of $\mathrm{B}$ - and T-cells, regulatory T-cells, and NK cells $(18,19)$. In NSCLCs, the expression of PD-L1 protein was shown to be predictive of the response to ICIs $(5,6,8-15)$. However, the expression of this protein can vary substantially between primary and metastatic lesions, as well as depending on the TME composition $(2,18)$. In general, M-NSCLCs are thought to be immunogenic and antiPD-1 or anti-PD-L1 antibodies are most effective when the TME is characterized by high levels of PD-L1 expression and a high density of TILs $(22,23,36)$. In the absence of TILs and positive PD-L1 expression on tumor cells, treatment with anti-PD-1 or anti-PD-L1 antibodies is expected to be less effective $(23,24,36)$. One possibility is also that TILs are present in the TME, but do not express PD-1, leading to an alternative immunosuppressive mechanism $(24,36)$. In addition to the PD-1/PD-L1 axis, other immune regulators such as myeloid-derived suppressor cells, tumor-associated macrophages, NK cells, dendritic cells, B-cells, and various chemokine/cytokine networks operate in the TME, which likely play important roles in defining the sensitivity of M-NSCLCs to ICIs (2, 22, 24, 26).

Some challenges of the prediction of the response to ICI in M-NSCLC come from methodological variabilities, as well as, various clinically approved cut-off scores for PD-L1 expression assessment $(37,38)$. First of all, there is no uniformity in PD-L1 assessment among numerous clinical trials that evaluated immune checkpoint inhibitors in M-NSCLC $(18,39)$. Moreover, these trials used different cut-offs for considering a sample as PD-L1 positive, as summarized in Table 1. Notably, some studies were based on a single biopsy assessment, making the results more susceptible to intratumor heterogeneity, whereas others relied on archival tissue in which the expression might change over the time (18, 40-42). Furthermore, data on PD-L1 testing in cytological specimens, which are the predominant sample type at some institutions, are limited (43). Moreover, IHC antibodies typically bind PD-L1 at only two small hydrophilic regions that make them structurally unique and might be differentially accessible in fresh frozen versus Formalin-fixed paraffin-embedded (FFPE) samples (18, 39, 41). Likewise, also glycosylation of PD-L1 could cause its polypeptide antigens inaccessible to $\mathrm{PD}-\mathrm{L} 1$ antibodies, which could lead to inaccurate IHC staining (44). Therefore, removal of the glycan moieties from PD-L1 to expose its polypeptide antigens has the potential to improve its detectability and to increase its utilization as a diagnostic biomarker to predict response to ICIs therapy (45). 
TABLE 1 | Characterization of $1 \mathrm{HC}$ assays used for PD-L1 assessment in different clinical trials.

\begin{tabular}{|c|c|c|c|c|c|c|}
\hline $\begin{array}{l}\text { PD-L1 clone } \\
\text { (species) }\end{array}$ & $\begin{array}{l}\text { Company } \\
\text { (platform) }\end{array}$ & $\begin{array}{l}\text { Tested ICI } \\
\text { (target) }\end{array}$ & $\begin{array}{l}\text { Trial(no. of } \\
\text { patients) }\end{array}$ & $\begin{array}{l}\text { Cell type for PD-L1 } \\
\text { scoring }\end{array}$ & $\begin{array}{l}\text { Percentage of PD-L1 positive } \\
\text { cells(cut-offs) }\end{array}$ & Indication \\
\hline $\begin{array}{l}22 \mathrm{C3} \\
\text { (Mouse) }\end{array}$ & $\begin{array}{l}\text { Dako } \\
\text { (Autostainer } \\
\text { Link 48) }\end{array}$ & $\begin{array}{l}\text { Pembrolizumab } \\
\text { (PD-1) }\end{array}$ & $\begin{array}{l}\text { KEYNOTE-001 } \\
(12) \\
(495) \\
\text { KEYNOTE-010 } \\
(9) \\
(1,034) \\
\text { KEYNOTE-024 } \\
(10) \\
(305) \\
\text { KEYNOTE-021 } \\
(11) \\
(123)\end{array}$ & Tumor cells & $\begin{array}{l}\mathrm{TC}<1 \% \\
\mathrm{TC} \geqslant 1 \% \\
\mathrm{TC} \geqslant 50 \% \\
\text { (min. of } 100 \mathrm{TC})\end{array}$ & $\begin{array}{l}\text { Second-line } \\
(\geqslant 1 \% \text { of } T C) \\
\text { First-line } \\
(\geqslant 50 \% \text { of } T C)\end{array}$ \\
\hline $\begin{array}{l}28-8 \\
\text { (Rabbit) }\end{array}$ & $\begin{array}{l}\text { Dako } \\
\text { (Autostainer } \\
\text { Link 48) }\end{array}$ & $\begin{array}{l}\text { Nivolumab } \\
\text { (PD-1) }\end{array}$ & $\begin{array}{l}\text { Checkmate- } \\
017(5) \\
(272) \\
\text { Checkmate- } \\
057(8) \\
(582) \\
\text { Checkmate- } \\
026(6) \\
(541)\end{array}$ & Tumor cells & $\begin{array}{l}\mathrm{TC}<1 \% \\
\mathrm{TC} \geqslant 1 \% \\
\mathrm{TC} \geqslant 5 \% \\
\mathrm{TC} \geqslant 10 \% \\
\text { (min. of } 100 \mathrm{TC} \text { ) }\end{array}$ & $\begin{array}{l}\text { Second-line regardless of PD-L1 } \\
\text { expression }\end{array}$ \\
\hline $\begin{array}{l}\text { SP142 } \\
\text { (Rabbit) }\end{array}$ & $\begin{array}{l}\text { Ventana } \\
\text { (BenchMark } \\
\text { ULTRA) }\end{array}$ & $\begin{array}{l}\text { Atezolizumab } \\
\text { (PD-L1) }\end{array}$ & $\begin{array}{l}\text { OAK (14) } \\
(850) \\
\text { POPLAR (15) } \\
(287)\end{array}$ & $\begin{array}{l}\text { Tumor cells, } \\
\text { Immune cells }\end{array}$ & $\begin{array}{l}\mathrm{TC}<1 \% \text { and } \mathrm{IC}<1 \% \\
\mathrm{TC} \geqslant 1 \% \text { or } \mathrm{IC} \geqslant 1 \% \\
\mathrm{TC} \geqslant 5 \% \text { or } \mathrm{IC} \geqslant 5 \% \\
\mathrm{TC} \geqslant 50 \% \text { or } \mathrm{IC} \geqslant 10 \% \\
\text { (min. of } 50 \mathrm{TC} \text { with associated } \\
\text { stroma) }\end{array}$ & $\begin{array}{l}\text { Second-line regardless of PD-L1 } \\
\text { expression }\end{array}$ \\
\hline $\begin{array}{l}\text { SP263 } \\
\text { (Rabbit) }\end{array}$ & $\begin{array}{l}\text { Ventana } \\
\text { (BenchMark } \\
\text { ULTRA) }\end{array}$ & $\begin{array}{l}\text { Durvalumab } \\
\text { (PD-L1) }\end{array}$ & $\begin{array}{l}\text { PACIFIC (13) } \\
(149)\end{array}$ & Tumor cells & $\begin{array}{l}T C<1 \% \\
T C \geqslant 1 \% \\
T C \geqslant 25 \% \\
\text { (min. of } 100 T C)\end{array}$ & $\begin{array}{l}\text { Maintenance therapy after } \\
\text { chemoradiotherapy ( } \geq 1 \% \text { of TC) }\end{array}$ \\
\hline $\begin{array}{l}\text { 73-10 } \\
\text { (Rabbit) }\end{array}$ & $\begin{array}{l}\text { Dako } \\
\text { (Autostainer } \\
\text { Link 48) }\end{array}$ & $\begin{array}{l}\text { Avelumab } \\
\text { (PD-L1) }\end{array}$ & $\begin{array}{l}\text { JAVELIN (17) } \\
(184)\end{array}$ & $\begin{array}{l}\text { Tumor cells, } \\
\text { Immune cells }\end{array}$ & $\begin{array}{l}\mathrm{TC}<1 \% \\
\mathrm{TC} \geqslant 1 \% \\
\text { (min. no of cells not defined) }\end{array}$ & Not approved \\
\hline
\end{tabular}

ICl, immunological checkpoint inhibitor; TC, tumor cells; IC, immune cells.

\section{Tumor Mutation Burden}

In addition to the TME and PD1/PD-L1, the amount of mutations expressed by a tumor-known as tumor mutation burden (TMB) - is another major determinant of the response of M-NSCLC patients to ICIs $(37,38,46)$. A summary of trials that have evaluated the association between the TMB and ICI efficacy is presented in Table 2. Several studies reported that TMB $\geq 10$ mutations per megabase (mut/Mb) is predictive of longer progression-free survival (PFS) and overall survival (OS) during ICI $(37,47)$. In addition, the B-F1RST trial reported that $\mathrm{TMB} \geq 16 \mathrm{mut} / \mathrm{Mb}$ in cell-free DNA is associated with significantly longer PFS (16). A higher TMB (>10 mut/Mb) was found in M-NSCLCs harboring driver mutations in KRAS or BRAF genes, but not in tumors with EGFR, ALK, ROS1, or MET gene mutations (3.1-6.2 mut/Mb) (48). Furthermore, adenocarcinomas were found to carry a lower TMB compared to squamous cell carcinomas $(9.1$ vs. $11.3 \mathrm{mut} / \mathrm{Mb}$ on average, respectively) (49). This observation might be explained by the fact that the etiology of adenocarcinomas is independent of tobacco exposure, making these tumors endowed with a lower neoantigen burden and therefore less immunogenic $(25,50)$.
The TMB is typically estimated based on either whole exome sequencing (WES) or targeted sequencing (TS) of the DNA extracted from a tumor $(46,51)$. However, these methodologies have different sequencing coverage and depth, and therefore provide a different sensitivity and specificity in estimating the TMB $(38,46,52)$. TS, which covers pre-specified small exonic or genomic regions, makes the assessment of the TMB easier, cheaper, and more practical in a clinical setting (37, $38,46,52)$. However, TS panels cover a substantially smaller fraction of the genome compare to WES probes, carrying the risk of actual TMB underestimation $(53,54)$. It was suggested that TS panels covering less than 300 genes or $1 \mathrm{Mb}$ cause unreliable TMB results and should be avoided (54). Importantly, a crucial step in correctly estimating the TMB is the bioinformatic selection of tumor-specific single-nucleotide variants (SNVs) by filtering out germline or synonymous SNVs, which represent false positives and are unlikely involved in neoantigen generation, respectively $(55,56)$. Likewise to tumor-specific SNVs, also frameshift indels (small insertions and deletions) are considered a highly immunogenic mutational class that trigger an increased quantity of 
TABLE 2 | Summary of clinical trials that have evaluated different TMB cut-offs for predicting the response to immunotherapy.

\begin{tabular}{|c|c|c|c|c|c|c|c|}
\hline \multirow[t]{2}{*}{ Trial } & \multirow[t]{2}{*}{ Treatment arms } & \multirow[t]{2}{*}{ Cut-off (mutation per megabase) } & \multirow[t]{2}{*}{ No. of patients } & \multicolumn{2}{|c|}{ os } & \multicolumn{2}{|c|}{ PFS } \\
\hline & & & & Median & HR & Median & HR \\
\hline \multirow[t]{2}{*}{ CheckMate 026 (6) } & NIVO vs CTH & High TMB & 107 & 18.3 & 1.1 & 9.7 & 0.62 \\
\hline & & Low or medium & 195 & 12.7 & 0.99 & 4.1 & 1.82 \\
\hline \multirow{2}{*}{ CheckMate 227 (7) } & $\mathrm{NIVO}+\mathrm{IPI}$ vs CTH & $\mathrm{TMB} \geq 10$ & 199 & & & 7.2 & 0.58 \\
\hline & & $\mathrm{TMB}<10$ & 380 & & & 3.2 & 1.07 \\
\hline \multirow[t]{3}{*}{ OAK (14) } & ATEZO vs. CTH & $\mathrm{TMB} \geq 10$ & 251 & & 0.69 & & 0.73 \\
\hline & & $\mathrm{TMB} \geq 16$ & 158 & & 0.64 & & 0.65 \\
\hline & & $\mathrm{TMB} \geq 20$ & 105 & & 0.65 & & 0.61 \\
\hline \multirow[t]{3}{*}{ POPLAR (13) } & ATEZO vs. CTH & $\mathrm{TMB} \geq 10$ & 96 & & 0.59 & & 0.67 \\
\hline & & $\mathrm{TMB} \geq 16$ & 63 & & 0.56 & & 0.57 \\
\hline & & $\mathrm{TMB} \geq 20$ & 42 & & 0.51 & & 0.58 \\
\hline \multirow[t]{8}{*}{ B-F1RST (16) } & ATEZO & $\mathrm{bTMB} \geq 12$ & 22 & & & 3 & 0.95 \\
\hline & & bTMB $<12$ & 36 & & & 3.2 & \\
\hline & & $\mathrm{bTMB} \geq 14$ & 14 & & & 3.4 & 0.73 \\
\hline & & bTMB $<14$ & 44 & & & 3.2 & \\
\hline & & $\mathrm{bTMB} \geq 16$ & 14 & & & 9.5 & 0.49 \\
\hline & & $\mathrm{bTMB}<16$ & 47 & & & 2.8 & \\
\hline & & bTMB $\geq 20$ & 8 & & & 9.5 & 0.23 \\
\hline & & bTMB $<20$ & 50 & & & 2.7 & \\
\hline
\end{tabular}

ATEZO, atezolizumab; CTH, chemotherapy; HR, hazard ratio; IPI, ipilimumab; NIVO, nivolumab; OS, overall survival; PFS, progression-free survival; TMB, tumor mutational burden; bTMB, blood based TMB.

neoantigen, moreover, it was reported that both the SNPs and frameshift burdens are significantly associated with ICIs response (57). In addition, pre-analytical and analytical factors such as the use of FFPE samples as a source of genomic DNA, a low tumor purity or a dense TME reduce the sensitivity of TMB determination, both for TS and WES $(38,46,47,51)$.

\section{Neoantigens}

Neoantigens are proteins with modified epitopes because of somatic mutations in their coding genes. These epitopes are loaded onto HLA molecules and displayed on the surface of tumor cells $(25,58)$. Neoantigens can be recognized as foreign by the host's immune system, ultimately triggering a T-cell mediated antitumor response $(50,58)$. A higher TMB is expected to increase the likelihood of recognition of the tumor by neoantigen-reactive T-cells (59). In M-NSCLC patients, the co-existence of a high TMB and neoantigen expression has a positive predictive value of the response to anti-PD1, anti-PD-L1 and anti-CTLA-4 therapy $(13,60)$. Some studies have suggested that neoantigen heterogeneity may influence immune surveillance, however, clonal and subclonal neoantigens do not drive equally immunogenicity $(13,50,59)$. Mutations induced by cytotoxic therapy enhance the subclonal neoantigens burden and might not elicit an effective antitumor response $(50,61)$. On the other hand, the extensive clonal mutational repertoire present in smoking-associated M-NSCLC (5) could render this disease sensitive to $\mathrm{T}$-cell therapies targeting multiple clonal neoantigens, in combination with appropriate modulation of immune checkpoints (50). Likewise, the observation that the expression of neoantigens is subjected to the genetic control may have important implications for predicting the response and resistance to ICIs, and might be harnessed to develop vaccines or adoptive cell therapies $(25,58,62)$. Activity of T-cells by the amount of neoantigens expressed within the tumor is regulated by the inflammatory microenvironment that controls the availability of immune-regulatory checkpoints for T-cell (22, $28,63,64)$. Tumor subclones expressing neoantigens may be preferentially eliminated by the immune system resulting in neoantigen loss (25). However, it is unclear which neoantigens are depleted as the result of the response to the therapy or tumor dissemination, and whether such phenomena only lead to tumor escape or may be harnessed to improve the response $(25,50$, $58,62)$.

\section{THE ROLE OF INTRATUMOR HETEROGENEITY}

In M-NSCLC, both spatial and temporal heterogeneity are considered as a main indicators of tumor diversity (65-67). The spatial type of ITH is related to discrepancies between different regions within the same tumor and may be detected at genetic and immunological level leading to a heterogeneous immune response in distinct populations of cancer cells (65, $66,68-70)$. The expression of PD-1 or PD-L1 might vary considerably from region to region within the same tumor, as a result of somatically acquired genetic differences. Up to $40 \%$ of M-NSCLC patients have substantially different anti$\mathrm{PD}-1$ resistance scores in different regions of the same tumor, which often leads to discordant predictions of the extent of response to anti-PD-1 or anti-PD-L1 inhibitors $(41,70)$. Depending on the study, $2-46 \%$ of small biopsy samples were found to give false-negative PD-L1 expression results in comparison to surgically resected specimens $(40-42,71,72)$. Moreover, in M-NSCLC, the heterogeneity of PD-L1 expression is also observed not only within the primary tumor, but also within and between coexisting metastases 
(40, 70-72). The metastatic sites may affect the value of PD-L1 as a predictive biomarker for ICIs treatment in NSCLC. Namely, specimens from lymph node metastases have low PD-L1 expression and are not preferred to guide ICIs treatment in clinical practice or in clinical trials (65). Among distant metastases of NSCLC, liver and adrenal sites have high PD-L1 expression, whereas it is low in brain and bones metastases $(65,73)$. Low PD-L1 expression in brain metastases may be related to the immune sanctuary features of this site $(65,67)$, whereas, bone tissues have a small pool of effective cytotoxic immune cells and a relatively large accumulation of suppressor immune cells $(65,74)$. This immune imbalance may favor the development of bone metastases with less selective pressure from the immune system, making PD-L1 expression in bone metastases less important for immune escape $(65,69,74)$. On the other hand, liver and adrenal glands are immunologically equipped for effective tumor surveillance with potent cytotoxic T-cells and, therefore, they require inhibitory mechanisms, like upregulation of PD-L1 expression, for cancer cells to survive (65, 69, 73).

In contrast to the spatial ITH, the temporal heterogeneity is created in between different time points during the disease course (67). The anticancer therapies may increase genetic ITH by shaping a new subclones with different somatic mutations, moreover, tumors with a highly heterogeneous subclonal structure might not produce enough neoantigens for T-cells to mount an effective anti-tumor response upon treatment with ICIs $(46,47,50,75)$. It was reported that the first line of MNSCLC treatment may potentially affect immune response during cancer evolution leading to the response to ICIs in various ways $(75,76)$. In overall, chemotherapy, radiotherapy, and EGFR or ALK tyrosine kinase inhibitors increase PD-L1 expression, suggesting that up-regulation of $\mathrm{PD}-\mathrm{L} 1$ is one approach that cancer cells may use to evade immunemediated cell destruction $(65,77-79)$. It is worth to add that increase of PD-L1 expression after administration of the cytotoxic agents is insignificant, whereas ICIs significantly decrease the PD-L1 expression within M-NSCLC $(65,79)$. Today, the decision whether to administer ICIs to M-NSCLC patients is based on PD-L1 staining in primary lesions (80). However, considering the above mentioned facts that the PDL1 status might change during treatment, all M-NSCLC patients should be re-biopsied and tested for PD-L1 expression upon therapy failure or at the time of disease progression (81).

In addition to genetic ITH, also non-genetic heterogeneity might influence the response of M-NSCLC patients to ICIs. As mentioned above, the heterogeneity of the TME can affect pathological stage, treatment efficacy and prognosis (29), and is an important predictor of antitumor response $(22,24)$. For example, the amount of desmoplastic stroma and the balance between promoting and inhibiting angiogenic factors (e.g. the vascular endothelial growth factor, VEGF) may influence the penetration of ICIs in the TME $(82,83)$. Additional spatial heterogeneities in the TME might cause an uneven penetration of these agents and contribute to the emergence of resistant cell populations or to the development of hypoxic niches that might support cancer stem cell phenotypes and immune evasion $(21,29,84)$. Furthermore, in M-NSCLC, the tumor immune evasion capacity may be modulated at different stages of the disease either by factors stimulating the tumor immune escape or through the loss of neoantigens expression $(25,50$, 62). Also spatial heterogeneity of intratumoral T-cells may be driven by the intratumoral neoantigen load and sculpted by a mutational background $(25,85)$.

\section{CONCLUSIONS AND FUTURE PERSPECTIVES}

Immunotherapy based on ICIs has drastically changed the natural history of many patients with M-NSCLC. However, the path towards ensuring long-term survival to most $\mathrm{M}$ NSCLC patients remains steep. Inter-patient differences in the composition and spatial structure of the TME and in the TMB influence the type and duration of response to ICIs and ultimately explain why certain patients, unlike others, have only a limited benefit from these agents. Genetic and phenotypic ITH is an important barrier limiting the effects of single-agent immune therapies. On the other hand, ITH might represent a vulnerable "Achilles' heel" that might be targeted by combinatorial therapies and/or adaptative strategies $(29,86)$. More studies on ITH are needed to understand the complex interplay between tumor and immune cells and the role of spatio-temporal tumor heterogeneity in the response of $\mathrm{M}$ NSCLC patients to immunotherapies. Single-cell approaches based on single-cell-sequencing or spatial transcriptomic may bring us an important step closer to understanding the role of ITH on response to ICI (87-89). Ultimately, this should lead to the development of novel therapeutic agents and/or treatment modalities, improving the prognosis of this still largely prevalent and deadly cancer.

\section{AUTHOR CONTRIBUTIONS}

All authors contributed to conception of the minireview. MN wrote the first draft of the manuscript and sections of the manuscript. PK, NC, and JM contributed to the draft of the manuscript revision. All authors contributed to the article and approved the submitted version.

\section{FUNDING}

This work was supported by a grant from the Polish National Science Center (UMO- 2016/23/D/NZ2/02890) and a START scholarship from the Foundation for Polish Science (FNP) to $\mathrm{MN}$, and Funds from Medical University of Lublin to JM. 


\section{REFERENCES}

1. Steven A, Fisher SA, Robinson BW. Immunotherapy for lung cancer. Respirol Carlton Vic (2016) 21:821-33. doi: 10.1111/resp.12789

2. Villanueva N, Bazhenova L. New strategies in immunotherapy for lung cancer: beyond PD-1/PD-L1. Ther Adv Respir Dis (2018) 12:1753466618794133. doi: $10.1177 / 1753466618794133$

3. Pabani A, Butts CA. Current landscape of immunotherapy for the treatment of metastatic non-small-cell lung cancer. Curr Oncol Tor Ont (2018) 25:S94S102. doi: $10.3747 /$ co.25.3750

4. Guo ZS. The 2018 Nobel Prize in medicine goes to cancer immunotherapy (editorial for BMC cancer). BMC Cancer (2018) 18. doi: 10.1186/s12885-0185020-3

5. Brahmer J, Reckamp KL, Baas P, Crinò L, Eberhardt WEE, Poddubskaya E, et al. Nivolumab versus Docetaxel in Advanced Squamous-Cell Non-Small-Cell Lung Cancer. N Engl J Med (2015) 373:123-35. doi: 10.1056/NEJMoa1504627

6. Carbone DP, Reck M, Paz-Ares L, Creelan B, Horn L, Steins M, et al. FirstLine Nivolumab in Stage IV or Recurrent Non-Small-Cell Lung Cancer. N Engl J Med (2017) 376:2415-26. doi: 10.1056/NEJMoa1613493

7. Hellmann MD, Ciuleanu T-E, Pluzanski A, Lee JS, Otterson GA, Audigier-Valette C, et al. Nivolumab plus Ipilimumab in Lung Cancer with a High Tumor Mutational Burden. N Engl J Med (2018) 378:2093104. doi: 10.1056/NEJMoa1801946

8. Borghaei H, Paz-Ares L, Horn L, Spigel DR, Steins M, Ready NE, et al. Nivolumab versus Docetaxel in Advanced Nonsquamous Non-Small-Cell Lung Cancer. N Engl J Med (2015) 373:1627-39. doi: 10.1056/NEJMoa1507643

9. Herbst RS, Baas P, Kim D-W, Felip E, Pérez-Gracia JL, Han J-Y, et al. Pembrolizumab versus docetaxel for previously treated, PD-L1-positive, advanced non-small-cell lung cancer (KEYNOTE-010): a randomised controlled trial. Lancet Lond Engl (2016) 387:1540-50. doi: 10.1016/S01406736(15)01281-7

10. Reck M, Rodríguez-Abreu D, Robinson AG, Hui R, Csőszi T, Fülöp A, et al. Pembrolizumab versus Chemotherapy for PD-L1-Positive Non-Small-Cell Lung Cancer. N Engl J Med (2016) 375:1823-33. doi: 10.1056/NEJMoa1606774

11. Langer CJ, Gadgeel SM, Borghaei H, Papadimitrakopoulou VA, Patnaik A, Powell SF, et al. Carboplatin and pemetrexed with or without pembrolizumab for advanced, non-squamous non-small-cell lung cancer: a randomised, phase 2 cohort of the open-label KEYNOTE-021 study. Lancet Oncol (2016) 17:1497-508. doi: 10.1016/S1470-2045(16)30498-3

12. Garon EB, Rizvi NA, Hui R, Leighl N, Balmanoukian AS, Eder JP, et al. Pembrolizumab for the treatment of non-small-cell lung cancer. N Engl J Med (2015) 372:2018-28. doi: 10.1056/NEJMoa1501824

13. Rizvi NA, Brahmer JR, Ou S-HI, Segal NH, Khleif S, Hwu W-J, et al. Safety and clinical activity of MEDI4736, an anti-programmed cell death-ligand 1 (PD-L1) antibody, in patients with non-small cell lung cancer (NSCLC). J Clin Oncol (2015) 33:8032-2. doi: 10.1200/jco.2015.33.15_suppl.8032

14. Rittmeyer A, Barlesi F, Waterkamp D, Park K, Ciardiello F, von Pawel J, et al. Atezolizumab versus docetaxel in patients with previously treated non-smallcell lung cancer (OAK): a phase 3, open-label, multicentre randomised controlled trial. Lancet Lond Engl (2017) 389:255-65. doi: 10.1016/S01406736(16)32517-X

15. Fehrenbacher L, Spira A, Ballinger M, Kowanetz M, Vansteenkiste J, Mazieres J, et al. Atezolizumab versus docetaxel for patients with previously treated nonsmall-cell lung cancer (POPLAR): a multicentre, open-label, phase 2 randomised controlled trial. Lancet Lond Engl (2016) 387:1837-46. doi: 10.1016/S0140-6736(16)00587-0

16. Gandara DR, Paul SM, Kowanetz M, Schleifman E, Zou W, Li Y, et al. Bloodbased tumor mutational burden as a predictor of clinical benefit in non-smallcell lung cancer patients treated with atezolizumab. Nat Med (2018) 24:14418. doi: 10.1038/s41591-018-0134-3

17. Gulley JL, Rajan A, Spigel DR, Iannotti N, Chandler J, Wong DJL, et al. Avelumab for patients with previously treated metastatic or recurrent nonsmall-cell lung cancer (JAVELIN Solid Tumor): dose-expansion cohort of a multicentre, open-label, phase 1b trial. Lancet Oncol (2017) 18:599-610. doi: 10.1016/S1470-2045(17)30240-1

18. Ancevski Hunter K, Socinski MA, Villaruz LC. PD-L1 Testing in Guiding Patient Selection for PD-1/PD-L1 Inhibitor Therapy in Lung Cancer. Mol Diagn Ther (2018) 22:1-10. doi: 10.1007/s40291-017-0308-6
19. Teixidó C, Vilariño N, Reyes R, Reguart N. PD-L1 expression testing in nonsmall cell lung cancer. Ther Adv Med Oncol (2018) 10:1758835918763493. doi: $10.1177 / 1758835918763493$

20. Gide TN, Quek C, Menzies AM, Tasker AT, Shang P, Holst J, et al. Distinct Immune Cell Populations Define Response to Anti-PD-1 Monotherapy and Anti-PD-1/Anti-CTLA-4 Combined Therapy. Cancer Cell (2019) 35:23855.e6. doi: 10.1016/j.ccell.2019.01.003

21. Osipov A, Saung MT, Zheng L, Murphy AG. Small molecule immunomodulation: the tumor microenvironment and overcoming immune escape. J Immunother Cancer (2019) 7:224. doi: 10.1186/s40425-019-0667-0

22. Binnewies M, Roberts EW, Kersten K, Chan V, Fearon DF, Merad M, et al. Understanding the tumor immune microenvironment (TIME) for effective therapy. Nat Med (2018) 24:541-50. doi: 10.1038/s41591-018-0014-x

23. Son B, Lee S, Youn H, Kim E, Kim W, Youn B. The role of tumor microenvironment in therapeutic resistance. Oncotarget (2017) 8:3933-45. doi: 10.18632/oncotarget.13907

24. Balkwill FR, Capasso M, Hagemann T. The tumor microenvironment at a glance. J Cell Sci (2012) 125:5591-6. doi: 10.1242/jcs.116392

25. Rosenthal R, Cadieux EL, Salgado R, Bakir MA, Moore DA, Hiley CT, et al. Neoantigen-directed immune escape in lung cancer evolution. Nature (2019) 567:479-85. doi: 10.1038/s41586-019-1032-7

26. Yu Y, Cui J. Present and future of cancer immunotherapy: A tumor microenvironmental perspective. Oncol Lett (2018) 16:4105-13. doi: 10.3892/ol.2018.9219

27. Kalluri R. The biology and function of fibroblasts in cancer. Nat Rev Cancer (2016) 16:582-98. doi: 10.1038/nrc.2016.73

28. Swartz MA, Iida N, Roberts EW, Sangaletti S, Wong MH, Yull FE, et al. Tumor Microenvironment Complexity: Emerging Roles in Cancer Therapy. Cancer Res (2012) 72:2473-80. doi: 10.1158/0008-5472.CAN-12-0122

29. Junttila MR, de Sauvage FJ. Influence of tumour micro-environment heterogeneity on therapeutic response. Nature (2013) 501:346-54. doi: 10.1038 /nature 12626

30. Galon J, Mlecnik B, Bindea G, Angell HK, Berger A, Lagorce C, et al. Towards the introduction of the 'Immunoscore' in the classification of malignant tumours. J Pathol (2014) 232:199-209. doi: 10.1002/path.4287

31. Li J, Li X, Zhang C, Zhang C, Wang H. A signature of tumor immune microenvironment genes associated with the prognosis of non-small cell lung cancer. Oncol Rep (2020) 43:795-806. doi: 10.3892/or.2020.7464

32. Stankovic B, Bjørhovde HAK, Skarshaug R, Aamodt H, Frafjord A, Müller E, et al. Immune Cell Composition in Human Non-small Cell Lung Cancer. Front Immunol (2019) 9:3101. doi: 10.3389/fimmu.2018.03101

33. Galon J, Bruni D. Approaches to treat immune hot, altered and cold tumours with combination immunotherapies. Nat Rev Drug Discovery (2019) 18:197218. doi: 10.1038/s41573-018-0007-y

34. Angell H, Galon J. From the immune contexture to the Immunoscore: the role of prognostic and predictive immune markers in cancer. Curr Opin Immunol (2013) 25:261-7. doi: 10.1016/j.coi.2013.03.004

35. Ventola CL. Cancer Immunotherapy, Part 3: Challenges and Future Trends. Pharm Ther (2017) 42:514-21.

36. Teng MWL, Ngiow SF, Ribas A, Smyth MJ. Classifying Cancers Based on Tcell Infiltration and PD-L1. Cancer Res (2015) 75:2139-45. doi: 10.1158/00085472.CAN-15-0255

37. Berland L, Heeke S, Humbert O, Macocco A, Long-Mira E, Lassalle S, et al. Current views on tumor mutational burden in patients with non-small cell lung cancer treated by immune checkpoint inhibitors. J Thorac Dis (2019) 11: S71-80. doi: 10.21037/jtd.2018.11.102

38. Galuppini F, Dal Pozzo CA, Deckert J, Loupakis F, Fassan M, Baffa R, et al. Tumor mutation burden: from comprehensive mutational screening to the clinic. Cancer Cell Int (2019) 19:209. doi: 10.1186/s12935-019-0929-4

39. Krawczyk P, Jarosz B, Kucharczyk T, Grenda A, Reszka K, Pankowski J, et al. Immunohistochemical assays incorporating SP142 and 22C3 monoclonal antibodies for detection of PD-L1 expression in NSCLC patients with known status of EGFR and ALK genes. Oncotarget (2017) 8:64283-93. doi: 10.18632/oncotarget.19724

40. McLaughlin J, Han G, Schalper KA, Carvajal-Hausdorf D, Pelekanou V, Rehman J, et al. Quantitative Assessment of the Heterogeneity of PD-L1 Expression in Non-Small-Cell Lung Cancer. JAMA Oncol (2016) 2:46-54. doi: 10.1001/jamaoncol.2015.3638 
41. Kerr KM, Nicolson MC. Non-Small Cell Lung Cancer, PD-L1, and the Pathologist. Arch Pathol Lab Med (2016) 140:249-54. doi: 10.5858/ arpa.2015-0303-SA

42. Gniadek TJ, Li QK, Tully E, Chatterjee S, Nimmagadda S, Gabrielson E. Heterogeneous expression of PD-L1 in pulmonary squamous cell carcinoma and adenocarcinoma: implications for assessment by small biopsy. Mod Pathol Off J U S Can Acad Pathol Inc (2017) 30:530-8. doi: 10.1038/modpathol. 2016.213

43. Sholl LM, Aisner DL, Allen TC, Beasley MB, Borczuk AC, Cagle PT, et al. Programmed Death Ligand-1 Immunohistochemistry-A New Challenge for Pathologists: A Perspective From Members of the Pulmonary Pathology Society. Arch Pathol Lab Med (2016) 140:341-4. doi: 10.5858/arpa.2015-0506-SA

44. Li C-W, Lim S-O, Xia W, Lee H-H, Chan L-C, Kuo C-W, et al. Glycosylation and stabilization of programmed death ligand-1 suppresses T-cell activity. Nat Commun (2016) 7:12632-43. doi: 10.1038/ncomms12632

45. Lee H-H, Wang Y-N, Xia W, Chen C-H, Rau K-M, Ye L, et al. Removal of Nlinked glycosylation enhances PD-L1 detection and predicts anti-PD-1/PD-L1 therapeutic efficacy. Cancer Cell (2019) 36:168-78.e4. doi: 10.1016/ j.ccell.2019.06.008

46. Chan TA, Yarchoan M, Jaffee E, Swanton C, Quezada SA, Stenzinger A, et al. Development of tumor mutation burden as an immunotherapy biomarker: utility for the oncology clinic. Ann Oncol (2019) 30:44-56. doi: 10.1093/annonc/ mdy495

47. Stenzinger A, Allen JD, Maas J, Stewart MD, Merino DM, Wempe MM, et al. Tumor mutational burden standardization initiatives: Recommendations for consistent tumor mutational burden assessment in clinical samples to guide immunotherapy treatment decisions. Genes Chromosomes Cancer (2019) 58:578-88. doi: $10.1002 /$ gcc.22733

48. Schrock AB, Li SD, Frampton GM, Suh J, Braun E, Mehra R, et al. Pulmonary Sarcomatoid Carcinomas Commonly Harbor Either Potentially Targetable Genomic Alterations or High Tumor Mutational Burden as Observed by Comprehensive Genomic Profiling. J Thorac Oncol Off Publ Int Assoc Study Lung Cancer (2017) 12:932-42. doi: 10.1016/j.jtho.2017.03.005

49. Skoulidis F, Goldberg ME, Greenawalt DM, Hellmann MD, Awad MM, Gainor JF, et al. STK11/LKB1 Mutations and PD-1 Inhibitor Resistance in KRAS-Mutant Lung Adenocarcinoma. Cancer Discovery (2018) 8:822-35. doi: 10.1158/2159-8290.CD-18-0099

50. McGranahan N, Furness AJS, Rosenthal R, Ramskov S, Lyngaa R, Saini SK, et al. Clonal neoantigens elicit $\mathrm{T}$ cell immunoreactivity and sensitivity to immune checkpoint blockade. Science (2016) 351:1463-9. doi: 10.1126/science.aaf1490

51. Van Allen EM, Wagle N, Stojanov P, Perrin DL, Cibulskis K, Marlow S, et al. Whole-exome sequencing and clinical interpretation of formalin-fixed, paraffin-embedded tumor samples to guide precision cancer medicine. Nat Med (2014) 20:682-8. doi: 10.1038/nm.3559

52. Li MM, Datto M, Duncavage EJ, Kulkarni S, Lindeman NI, Roy S, et al. Standards and Guidelines for the Interpretation and Reporting of Sequence Variants in Cancer. J Mol Diagn JMD (2017) 19:4-23. doi: 10.1016/ j.jmoldx.2016.10.002

53. Buchhalter I, Rempel E, Endris V, Allgäuer M, Neumann O, Volckmar A-L, et al. Size matters: Dissecting key parameters for panel-based tumor mutational burden analysis. Int J Cancer (2019) 144:848-58. doi: 10.1002/ijc.31878

54. Chalmers ZR, Connelly CF, Fabrizio D, Gay L, Ali SM, Ennis R, et al. Analysis of 100,000 human cancer genomes reveals the landscape of tumor mutational burden. Genome Med (2017) 9(1):34. doi: 10.1186/s13073-017-0424-2

55. McKenna A, Hanna M, Banks E, Sivachenko A, Cibulskis K, Kernytsky A, et al. The Genome Analysis Toolkit: A MapReduce framework for analyzing next-generation DNA sequencing data. Genome Res (2010) 20:1297-303. doi: 10.1101/gr.107524.110

56. Garofalo A, Sholl L, Reardon B, Taylor-Weiner A, Amin-Mansour A, Miao D, et al. The impact of tumor profiling approaches and genomic data strategies for cancer precision medicine. Genome Med (2016) 8:79-88. doi: 10.1186/ s13073-016-0333-9

57. Turajlic S, Litchfield K, Xu H, Rosenthal R, McGranahan N, Reading JL, et al. Insertion-and-deletion-derived tumour-specific neoantigens and the immunogenic phenotype: a pan-cancer analysis. Lancet Oncol (2017) 18:1009-21. doi: 10.1016/S1470-2045(17)30516-8

58. Schumacher TN, Schreiber RD. Neoantigens in cancer immunotherapy. Science (2015) 348:69-74. doi: 10.1126/science.aaa4971
59. Hellmann MD, Nathanson T, Rizvi H, Creelan BC, Sanchez-Vega F, Ahuja A, et al. Genomic Features of Response to Combination Immunotherapy in Patients with Advanced Non-Small-Cell Lung Cancer. Cancer Cell (2018) 33:843-52.e4. doi: 10.1016/j.ccell.2018.03.018

60. Van Allen EM, Miao D, Schilling B, Shukla SA, Blank C, Zimmer L, et al. Genomic correlates of response to CTLA-4 blockade in metastatic melanoma. Science (2015) 350:207-11. doi: 10.1126/science.aad0095

61. Be J, Mazor T, Hong C, Barnes M, Aihara K, McLean CY, et al. Mutational analysis reveals the origin and therapy-driven evolution of recurrent glioma. Sci (N Y NY) (2014) 343:189-93. doi: 10.1126/science.1239947

62. Anagnostou V, Smith KN, Forde PM, Niknafs N, Bhattacharya R, White J, et al. Evolution of Neoantigen Landscape during Immune Checkpoint Blockade in Non-Small Cell Lung Cancer. Cancer Discovery (2017) 7:26476. doi: 10.1158/1538-7445.AM2017-NG01

63. McGranahan N, Swanton C. Biological and therapeutic impact of intratumor heterogeneity in cancer evolution. Cancer Cell (2015) 27:15-26. doi: 10.1016/ j.ccell.2014.12.001

64. Rooney MS, Shukla SA, Wu CJ, Getz G, Hacohen N. Molecular and genetic properties of tumors associated with local immune cytolytic activity. Cell (2015) 160:48-61. doi: 10.1016/j.cell.2014.12.033

65. Hong L, Negrao MV, Dibaj SS, Chen R, Reuben A, Bohac JM, et al. Programmed Death-Ligand 1 Heterogeneity and Its Impact on Benefit From Immune Checkpoint Inhibitors in NSCLC. J Thorac Oncol (2020) 15:1449-59. doi: 10.1016/j.jtho.2020.04.026

66. Zhang J, Fujimoto J, Zhang J, Wedge DC, Song X, Zhang J, et al. Intratumor heterogeneity in localized lung adenocarcinomas delineated by multiregion sequencing. Science (2014) 346:256-9. doi: 10.1126/science.1256930

67. Mansfield AS, Aubry MC, Moser JC, Harrington SM, Dronca RS, Park SS, et al. Temporal and spatial discordance of programmed cell death-ligand 1 expression and lymphocyte tumor infiltration between paired primary lesions and brain metastases in lung cancer. Ann Oncol Off J Eur Soc Med Oncol (2016) 27:1953-8. doi: 10.1093/annonc/mdw289

68. Jamal-Hanjani M, Wilson GA, McGranahan N, Birkbak NJ, Watkins TBK, Veeriah S, et al. Tracking the Evolution of Non-Small-Cell Lung Cancer. N Engl J Med (2017) 376:2109-21. doi: 10.1056/NEJMoa1616288

69. Reuben A, Zhang J, Chiou S-H, Gittelman RM, Li J, Lee W-C, et al. Comprehensive $\mathrm{T}$ cell repertoire characterization of non-small cell lung cancer. Nat Commun (2020) 11:603-706. doi: 10.1038/s41467-019-14273-0

70. Lee W-C, Diao L, Wang J, Zhang J, Roarty EB, Varghese S, et al. Multiregion gene expression profiling reveals heterogeneity in molecular subtypes and immunotherapy response signatures in lung cancer. Mod Pathol Off J U S Can Acad Pathol Inc (2018) 31:947-55. doi: 10.1038/s41379-018-0029-3

71. Tsai EB, Pomykala K, Ruchalski K, Genshaft S, Abtin F, Gutierrez A, et al. Feasibility and Safety of Intrathoracic Biopsy and Repeat Biopsy for Evaluation of Programmed Cell Death Ligand-1 Expression for Immunotherapy in Non-Small Cell Lung Cancer. Radiology (2018) 287:326-32. doi: 10.1148/radiol.2017170347

72. Ilie M, Long-Mira E, Bence C, Butori C, Lassalle S, Bouhlel L, et al. Comparative study of the PD-L1 status between surgically resected specimens and matched biopsies of NSCLC patients reveal major discordances: a potential issue for antiPD-L1 therapeutic strategies. Ann Oncol Off J Eur Soc Med Oncol (2016) 27:147-53. doi: 10.1093/annonc/mdv489

73. Rizvi H, Bandlamudi C, Schoenfeld AJ, Sauter JL, Arbour KC, Beras A, et al. Molecular correlates of PD-L1 expression in patients with non-small cell lung cancer. J Clin Oncol (2019) 37:9018-8. doi: 10.1200/JCO.2019.37.15_suppl.9018

74. Baschuk N, Rautela J, Parker BS. Bone specific immunity and its impact on metastasis. BoneKEy Rep (2015) 4:665-711. doi: 10.1038/bonekey.2015.32

75. McGranahan N, Favero F, de Bruin EC, Birkbak NJ, Szallasi Z, Swanton C. Clonal status of actionable driver events and the timing of mutational processes in cancer evolution. Sci Transl Med (2015) 7:283ra54. doi: 10.1126/scitranslmed.aaa1408

76. Omori S, Kenmotsu H, Abe M, Watanabe R, Sugino T, Kobayashi H, et al. Changes in programmed death ligand 1 expression in non-small cell lung cancer patients who received anticancer treatments. Int J Clin Oncol (2018) 23:1052-9. doi: 10.1007/s10147-018-1305-4

77. Jiang L, Guo F, Liu X, Li X, Qin Q, Shu P, et al. Continuous targeted kinase inhibitors treatment induces upregulation of PD-L1 in resistant NSCLC. Sci Rep (2019) 9:3705. doi: 10.1038/s41598-018-38068-3 
78. Wang Y, Kim TH, Fouladdel S, Zhang Z, Soni P, Qin A, et al. PD-L1 Expression in Circulating Tumor Cells Increases during Radio(chemo) therapy and Indicates Poor Prognosis in Non-small Cell Lung Cancer. Sci Rep (2019) 9:566. doi: 10.1038/s41598-018-36096-7

79. Parra ER, Villalobos P, Behrens C, Jiang M, Pataer A, Swisher SG, et al. Effect of neoadjuvant chemotherapy on the immune microenvironment in nonsmall cell lung carcinomas as determined by multiplex immunofluorescence and image analysis approaches. J Immunother Cancer (2018) 6:48. doi: 10.1186/s40425-018-0368-0

80. Saito Y, Horiuchi S, Morooka H, Ibi T, Takahashi N, Ikeya T, et al. Intertumor heterogeneity of PD-L1 expression in non-small cell lung cancer. J Thorac Dis (2019) 11:4982-91. doi: 10.21037/jtd.2019.12.24

81. Zarogoulidis P, Papadopoulos V, Maragouli E, Papatsibas G, Karapantzos I, Bai C, et al. Tumor heterogenicity: multiple needle biopsies from different lesion sites-key to successful targeted therapy and immunotherapy. Transl Lung Cancer Res (2018) 7:S46-8. doi: 10.21037/tlcr.2018.01.07

82. Qiang H, Chang Q, Xu J, Qian J, Zhang Y, Lei Y, et al. New advances in antiangiogenic combination therapeutic strategies for advanced non-small cell lung cancer. J Cancer Res Clin Oncol (2020) 146:631-45. doi: 10.1007/s00432020-03129-6

83. Fukumura D, Kloepper J, Amoozgar Z, Duda DG, Jain RK. Enhancing cancer immunotherapy using antiangiogenics: opportunities and challenges. Nat Rev Clin Oncol (2018) 15:325-40. doi: 10.1038/nrclinonc.2018.29

84. Fu F, Nowak MA, Bonhoeffer S. Spatial heterogeneity in drug concentrations can facilitate the emergence of resistance to cancer therapy. PloS Comput Biol (2015) 11:e1004142. doi: 10.1371/journal.pcbi.1004142

85. TRACERx consortium, Joshi K, de Massy MR, Ismail M, Reading JL, Uddin I, et al. Spatial heterogeneity of the $\mathrm{T}$ cell receptor repertoire reflects the mutational landscape in lung cancer. Nat Med (2019) 25:1549-59. doi: 10.1038/s41591-0190592-2

86. McGranahan N, Swanton C. Clonal Heterogeneity and Tumor Evolution: Past, Present, and the Future. Cell (2017) 168:613-28. doi: 10.1016/ j.cell.2017.01.018

87. Gibellini L, De Biasi S, Porta C, Lo Tartaro D, Depenni R, Pellacani G, et al. Single-Cell Approaches to Profile the Response to Immune Checkpoint Inhibitors. Front Immunol (2020) 11:490-508. doi: 10.3389/fimmu.2020. 00490

88. Kim N, Kim HK, Lee K, Hong Y, Cho JH, Choi JW, et al. Single-cell RNA sequencing demonstrates the molecular and cellular reprogramming of metastatic lung adenocarcinoma. Nat Commun (2020) 11:2285. doi: 10.1038/ s41467-020-16164-1

89. Ma K-Y, Schonnesen AA, Brock A, Van Den Berg C, Eckhardt SG, Liu Z, et al. Single-cell RNA sequencing of lung adenocarcinoma reveals heterogeneity of immune response-related genes. JCI Insight (2019) 4:e121387. doi: 10.1172/ jci.insight. 121387

Conflict of Interest: The authors declare that the research was conducted in the absence of any commercial or financial relationships that could be construed as a potential conflict of interest.

Copyright $\odot 2020$ Nicoś, Krawczyk, Crosetto and Milanowski. This is an open-access article distributed under the terms of the Creative Commons Attribution License (CC BY). The use, distribution or reproduction in other forums is permitted, provided the original author(s) and the copyright owner(s) are credited and that the original publication in this journal is cited, in accordance with accepted academic practice. No use, distribution or reproduction is permitted which does not comply with these terms. 